\title{
How Investor Structure Influences the Yield, Information Dissemination Efficiency, and Liquidity
}

\author{
Hongli Che, ${ }^{1}$ Xiong Xiong, ${ }^{1,2}$ Juntian Yang, ${ }^{1}$ Wei Zhang, ${ }^{1,2}$ and Yongjie Zhang ${ }^{1,2}$ \\ ${ }^{1}$ College of Management and Economics, Tianjin University, Tianjin 300072, China \\ ${ }^{2}$ China Center for Social Computing and Analytics, Tianjin University, Tianjin 300072, China \\ Correspondence should be addressed to Juntian Yang; 296951233@qq.com
}

Received 8 March 2014; Accepted 12 May 2014; Published 25 May 2014

Academic Editor: Fenghua Wen

Copyright (c) 2014 Hongli Che et al. This is an open access article distributed under the Creative Commons Attribution License, which permits unrestricted use, distribution, and reproduction in any medium, provided the original work is properly cited.

\begin{abstract}
This essay focuses on the investor structure of the stock index futures market and uses agent-based computational finance method to discuss how the volume-synchronized probability of informed trading (VPIN) affects market absolute yield, information dissemination efficiency, and liquidity with different ratios of informed traders in the market. The result shows that the higher the proportion of informed traders is, the more the volatility of the market is. Furthermore, the result indicates that when the proportion of informed traders in the stock index futures market accounts for 1/3-1/2, the transparency and liquidity of the market will be better.
\end{abstract}

\section{Introduction}

Looking back, there were many risky activities led by financial innovation, such as the big crash caused by the use of portfolio insurance strategies in America, in 1987, and the flash crash of Dow triggered by the e-mini futures contracts in 2010. In 2010, the CSI 300 index futures were traded officially in China, which completely changed the structure of China's capital market. The financial derivatives can play a hedge effectiveness and expand investment channels, but the risks they bring should not be ignored. How to realize liquidity risk management from the perspective of investors' structure? How investor structure influences the yield? What is the relationship between information dissemination efficiency and investor structure? To solve the mystery, regulators and academics have done much research in this field and achieved a lot.

In the commodity economy, information is mainly reflected on the price; price information is the core of economic information. The nature of market economy is using price as a signal to allocate social resources. Distribution and redistribution of social resources are actually the processes during which people play games on the price. The preemption of any kind of resources makes related profit in the game, so does the information. In order to study the price discovery, hedging, and other issues of the stock market, traditional finance researches tend to assume that traders in the market have a common set of assumptions information. However, in reality, information on the financial markets can not be completely balanced, causing the interest imbalance between both sides, which imposes adverse effect on the social principle of justice and fairness, reducing the resource allocation efficiency in the market.

The key to solve the problem of asymmetric information problem is how to measure the degree of information asymmetry. Aiming at this, many scholars have generally studied the information contained in the orders for a long time. However, in recent years, the traditional methods for measurement have too many difficulties to cope with the problem. In a framework where trades take place in milliseconds, Easley et al. (2011) [1] introduced another conception. In this paper we apply this new technique to our study. In addition, the financial system is essentially a complex system in essence (Holland, 1997 [2]), and it is nonlinear and adaptive, which makes most theoretical models ineffective even after releasing the assumption. Fortunately, agent-based 
computational finance provides us with new train of thoughts and tactics to study the complex adaptive system.

Based on VPIN model submitted by Easley et al. (2011), and with the help of agent-based computational finance which has real market characteristics, we study the effect of how informed traders proportion imposes on market absolute yields, information dissemination efficiency, and liquidity by setting different investor structure. As for the method, this essay uses TBS-ASIFM model, which can reproduce extreme situation of information transaction at any time by setting parameters and help market regulators prevent risk events in advance.

This essay can provide trading strategy guidance for investors on stock index futures market and offer valuable political suggestions to the market regulators to prevent liquidity risk events. To be specific, the three main topics of this essay are as follows: how informed traders' proportion affects the market; the proportion within which scope is reasonable for the whole market's transparency and liquidity; how to manage liquidity risk from the point of investor structure.

This essay includes six sections: the second part is the literature review, which systematically reviews relevant research literature at home and abroad according to the main ideas; the third part introduces the EKOP model and the VPIN model; the forth part gives a more systematical description of TBSASIFM artificial financial market model used later, introduces the setting of the model's parameters, and shows and analyses the results of simulation experiments; the fifth part is the conclusion; and the final part is the prospect of our study.

\section{Literature Review}

Earlier scholars mainly used indirect methods to calculate the degree of information asymmetry on security markets. Until 1996, Easley et al. (1996) [3] established EKOP model to calculate the degree of information asymmetry directly for the first time. Then Easley et al. (1997) [4] optimized the EKOP model by considering more comprehensive indicators, such as trading time, and built a better information transaction probability model. Researches on financial market information transaction probability of Venter and de Jongh (2004) [5], Lei and Wu (2005) [6] released the hypothesis that the traders arrival rate is constant. Venter and de Jongh (2004) assumed that traders' order arrival rates on the market followed inverse Gaussian distribution, while Lei and $\mathrm{Wu}$ (2005) allowed order arrival rates of uninformed traders with the behavioral characteristics of the district system to convert endogenously. In view of high frequency financial market, Easley et al. (2011) probed a method to measure the market's information transaction probability based on trading volume. This method divided trading volume into a few volume buckets and applied new estimation methods to determine the offer direction of each trade in each volume bucket. Easley et al. (2012) [7] fully expounded the significance of applying volume clock to high frequency trade, verifying the applicability of the VPIN model indirectly.
The studies mentioned above are mostly theoretical studies, and their contents are limited to the design and extension of models. In other words, they only state the characteristics and possible application theoretically and do not conduct empirical analysis on specific objects, such as stock, bonds, and futures. Nyholm (2002 [8], 2003 [9]) studied market information transaction probability through separated high frequency data, and he used regime-switching model to explain the probability of informed trades from the brokers' point of view. Easley et al. (2010) [10] applied VPIN model into "flash crash" in 2010 and studied the change of VPIN of EMini S\&P 500 stock index futures market. The result indicates that, during the week before "flash crash," the submissions of the market orders were extremely unbalanced, information trades were very frequent, and the VPIN was also extremely unstable. Especially several hours before the "flash crash," the VPIN of the market reached an anomaly peak. Therefore, the buyers' liquidity of the market was insufficient when the "flash crash" began. Their study explained the "flash crash" theoretically, with insufficient discussion on informed traders' proportion. In the field of high-frequency trading, Huang et al. (2013) [11] took five-minute transaction data of China's CSI 300 index as the research object, established HAR-CJ-M model, and applied this model to the study of CSI 300 index volatility. The result shows that the volatility of Chinese stock market can be influenced by the past volatility components, and these different volatility components derived from behaviors of investors with different holding term limits (short term, medium term, and long term) owned by the behaviors of investors.

In recent years, agent-based computational finance, which is based on complex adaptive system theory and computer simulation modeling, has gradually risen and achieved marked achievements, combining complex adaptive system theory and behavioral finance theory and using objectoriented modeling method to construct a kind of artificial financial markets that have real market features (transaction mechanism, institutional arrangement, agent behavior patterns, and study mechanism). Using the method of ACF, researchers can extend their studies on microstructure, macroscopic properties, regular patterns, and other aspects of financial market, like Levy et al. (2000) [12]. LeBaron (2006) [13] pointed out that agent-based computational finance provided a new and exciting tool to solve problems that could not be solved by traditional models. Tesfatsion and Judd's (2006) "Agent-based computational finance" [14] indicated that the research paradigm of agent-based computational finance had taken initial shape.

In the aspect of empirical research, Lux and Marchesi (1999) [15] described a multiagent model, which classified investors into two types, namely, fundamentals and noise traders. Mike and Farmar (2008) [16] developed an agentbased model on the basis of the continuous double auction mechanism in an order-driven market, to solve liquidity and volatility problems. Gu and Zhou (2009) [17] proposed a modified version of the Mike-Farmar model by including a new ingredient, that is, long memory in the aggressiveness of incoming orders. The finding shows the memory effect of order aggressiveness has little impact on the diffusiveness 
of stock prices. Zhang et al. (2010) [18] used agent-based computational finance to investigate the investment yield of four kinds of investors (rational expectation strategy, BSV strategy, noise trading strategy, and passive trading strategy). The finding shows the combination of arbitrage limits, noise trading, and risk aversion; rational investors cannot "eliminate" BSV investors; all the evidence argued against the Friedman's hypothesis cannot be established. Based on Italian researcher's SUMWEB model, Xiong et al. (2011) [19] studied the impact laid by the design of cross-market risk from the view of market typical characteristics and trading mechanisms and analyzed the formation mechanism of cross-market risk. Zhang et al. (2011) [20] established two artificial financial markets, MD-ASIFM (mechanism design on artificial stock index future market) and TBSASIFM (trader's behavior and structure on artificial stock index future market), and then used MD-ASIFM to analyze the influence of tick size and optimal design of position limits on market quality. They also proposed a suggestion of optimal setting and used TBS-ASIFM to address the influence of investor's structure of stock index future market and programmed arbitrage strategy on market quality. It is worth noting that the empirical analysis in this paper is on the basis of the TBS-ASIFM.

\section{EKOP Model and VPIN Model}

3.1. EKOP Model. EKOP model was formulated based on the sequential trade model by Easley et al. (1996). It determines the probability of informed trading by calculating the proportion of informed traders in all the certain risk asset transactions. The settings of EKOP model in detail are as follows.

Market Mechanism. EKOP model is defined in the dealership market framework, and researchers assume that the market makers are risk-neutral and competitive. The price of an asset, which is calculated according to the expected price of all the past transaction information, is offered to the investors by the market makers sequentially and then promotes the trades among them.

Trading Period. The trading process of EKOP model presents a hybrid form of discrete and continuous time sequential model. Trading days as the discrete parts are expressed by $i(i=1, \ldots I)$, and the time within a trading day as the continuous part is expressed by $t \in[0, T]$. Information events are independently distributed. At the end of each trading day, the event will be fully reflected through the asset price. Simultaneously, the hypothesis that each investor just trades once during the course of the trading day and the transaction should be accomplished timely cannot be ignored.

Investors. In this model, there are informed and uninformed traders in the market. Informed traders can know in advance the risk of asset price; they enter markets and purchase risk assets when good news appears. When bad news occurs, such traders enter the market and sell risk assets. When there is no information incident happening in a trading day, informed traders would prefer to choose to wait and see. While for the uninformed traders who are completely unable to get information in advance, they enter markets according to other purposes (liquidity, psychological bias or hedge risk, etc.). The arrival rates of informed and uninformed traders, governed by independent Poisson processes, determine trades. The arrival rates also depend on the occurrence of three types of information events, namely, no news, good news, and bad news, which are chosen by nature every day. In each trading day, arrivals of uninformed buyers and uninformed sellers are determined by independent Poisson processes. Uninformed buyers and sellers arrive at rate $\varepsilon$. The arrival rate of informed buyers and sellers is instead $\mu$.

Asset. Before the beginning of each trading day, the incidence of information events is independently distributed and expressed as $\alpha$. These events are divided into two types, that is, good news with probability $1-\delta$ or bad news with probability $\delta$. After the end of trading on any day, the full information value of the asset is obtained. With the occurrence of an information event in day $i$, the value of the asset is either $\bar{S}_{i}$ with good news or $\underline{S}_{i}$ with bad news.

Informed Trading Probability. Define $P(t)=\left\{P_{n}(t), P_{b}(t)\right.$, $\left.P_{g}(t)\right\}$ as the market maker's prior belief about the events, no news $(n)$, bad news $(b)$, and good news $(g)$ at time $t$. The unconditional prior beliefs at time 0 are equal to the probabilities with which nature chooses the information regime; $P(0)=\{1-\alpha, \alpha * \delta, \alpha *(1-\delta)\}$. So at time $t$, the expected value of the risky assets of the market makers is shown as

$$
E\left(S_{i} t\right)=P_{n}(t) * S_{t}^{*}+P_{b}(t) * \underline{S}_{i}+P_{g}(t) * \bar{S}_{i} .
$$

At time $t$, the probability for the informed traders to sell the asset is given by $\mu * P_{b}(t) /\left(\varepsilon+\mu * P_{b}(t)\right)$. Similarly, the probability for the informed traders to buy the asset is given by $\mu * P_{g}(t) /\left(\varepsilon+\mu * P_{g}(t)\right)$. The bid and ask are given by the following relation:

$$
\begin{aligned}
& B(t)=E\left(S_{i} t\right)-\frac{\mu * P_{b}(t)}{\varepsilon+\mu * P_{b}(t)} *\left[E\left(S_{i} t\right)-\underline{S}_{i}\right], \\
& A(t)=E\left(S_{i} t\right)+\frac{\mu * P_{g}(t)}{\varepsilon+\mu * P_{g}(t)} *\left[\bar{S}_{i}-E\left(S_{i} t\right)\right] .
\end{aligned}
$$

These equations demonstrate the impact laid by arrivals of informed and uninformed traders on the market-makers quotes. If there are no informed traders $(\mu=0)$, then trade carries no information, and so the bid and ask are both equal to the prior expected value of the asset. Alternatively, if there are no uninformed traders $(\varepsilon=0)$, then the bid and ask are at the minimum and maximum prices, respectively. At these prices, no informed traders will trade either, and the market, in effect, shuts down. Generally, both informed and uninformed traders will be in the market, and so the bid is less than $E\left(S_{i} \mid t\right)$, and the ask is greater than $E\left(S_{i} \mid t\right)$. 
The bid-ask spread at time $t$ is denoted by

$$
\begin{aligned}
\Sigma(t)= & \frac{\mu * P_{g}(t)}{\varepsilon+\mu * P_{g}(t)}\left[\overline{S_{i}}-E\left(S_{i} \mid t\right)\right] \\
& +\frac{\mu * P_{b}(t)}{\varepsilon+\mu * P_{b}(t)}\left[E\left(S_{i} t\right)-\underline{S}_{i}\right] .
\end{aligned}
$$

The spread for the initial quotes in the period has a particularly simple form in the natural case in which good and bad events are equally likely. That is, if $\delta=1-\delta$, then

$$
\Sigma=\frac{\alpha * \mu}{\alpha * \mu+2 \varepsilon} *\left(\overline{S_{i}}-\underline{S}_{i}\right)
$$

So the probability that the information-based opening trade in a period is given by

$$
\mathrm{PIN}=\frac{\alpha * \mu}{\alpha * \mu+2 \varepsilon}
$$

Due to the indirectly observation such as the occurrence of information events or the associated arrival of informed and uninformed traders, it is difficult to estimate the parameter arise. However, knowing the daily arrivals of sell and buy is possible, which offers an excellent approach to inferring these values using maximum likelihood. Note that the trading process follows a Poisson process. Consider

$$
\begin{aligned}
L= & \prod_{i=1}^{n} P\left[y_{t}=\left(B_{t}, S_{t}\right)\right] \\
= & \prod_{i=1}^{n}\left(\alpha *(1-\delta) * e^{-(\mu+2 \varepsilon)} * \frac{(\mu+\varepsilon)^{B_{t}} * \varepsilon^{S_{t}}}{B_{t} ! * S_{t} !}\right. \\
& \left.+\alpha * \delta * e^{-(\mu+2 \varepsilon)} * \frac{(\mu+\varepsilon)^{S_{t}} * \varepsilon^{B_{t}}}{B_{t} ! * S_{t} !}\right) \\
& +(1-\alpha) * e^{-2 \varepsilon} * \frac{\varepsilon^{\left(B_{t}+S_{t}\right)}}{B_{t} ! * S_{t} !} .
\end{aligned}
$$

3.2. VPIN Model. Easley et al. (2011) grouped sequential trades into equal volume bucketsof an exogenously defined size $V$. A volume bucket is a collection of trades with total volume $V$. If the last trade is in need of a complete bucket which is greater than the requirement in size, the excess size is given to the next bucket. We let $\tau=1, \ldots, n$ be the index of equal volume buckets. If the deal is launched by the buyer, the sum of volume launches by buyers is marked as $V_{\tau}^{B}$ or marked as $V_{\tau}^{S}$. There will be

$$
\frac{1}{n} \sum_{\tau=1}^{n}\left(V_{\tau}^{B}+V_{\tau}^{S}\right)=V
$$

From EKOP model and Easley et al. (2008) [21], we can know the following:

$$
\begin{aligned}
& E(V) \\
& =\underbrace{\alpha *(1-\delta) *(\varepsilon+\mu+\varepsilon)}_{\text {volume resulting from good news }}+\underbrace{\alpha * \delta *(\mu+\varepsilon+\varepsilon)}_{\text {volume resulting from bad news }} \\
& +\underbrace{(1-\alpha) *(\varepsilon+\varepsilon)}_{\text {volume without news }}=\alpha * \mu+2 \varepsilon, \\
& E(O I)=B-S \\
& =\alpha * \delta *(\varepsilon-\mu-\varepsilon)+\alpha *(1-\delta) *(\varepsilon+\mu-\varepsilon) \\
& +(1-\alpha) *(\varepsilon-\varepsilon) \\
& =\alpha * \mu(1-2 \delta) \text {. } \\
& E(|O I|)=|B-S| \\
& =\alpha * \delta *(|\varepsilon-\mu-\varepsilon|)+\alpha *(1-\delta) *(|\varepsilon+\mu-\varepsilon|) \\
& +(1-\alpha) *(|\varepsilon-\varepsilon|) \\
& =\alpha * \mu \text {, } \\
& E\left[O I_{\tau}\right]=E\left[\left|V_{\tau}^{S}-V_{\tau}^{B}\right|\right] \approx \alpha * \mu .
\end{aligned}
$$

Generally speaking, information trading can be reflected by the unbalance order. So

$$
\mathrm{VPIN}=\frac{\alpha * \mu}{\alpha * \mu+2 \varepsilon}=\frac{\alpha * \mu}{V} \approx \frac{\sum_{r=1}^{n}\left|V_{\tau}^{S}-V_{\tau}^{B}\right|}{n * V}
$$

\section{TBS-ASIFM Artificial Financial Market and Empirical Analysis}

4.1. The Introduction of TBS-ASIFM Artificial Financial Market. TBS-ASIFM artificial financial market model includes a stock market and a stock index market. We can merchandise several stocks in the stock market but merchandise only one stock index in the stock index market. The investors in the two markets can be classified into three types. The first is risky assets value informed investors, the second is risky assets uninformed investors, and the third is liquid investors. Some investors are operating in both markets. TBSASIFM includes multiple assets, markets, and investors. All investors are fortune-restrained, limited by risk management and market trading mechanism. Simultaneously, the artificial financial market should conform with the rules of the stock market and the stock index market.

Market mechanism includes two parts: stock market and stock index market; both of them are continuous double auction trading mechanisms. The stock market chooses $T+1$ trading rules and the stock index market chooses the $T+0$ one.

Assets. There are 5 stocks and 1 stock index in the market. The stock index is combined by 5 stocks. The settings of 
traders' transactions and trading strategies can be learned from Zhang et al. (2011).

The investors trading in the stock market can be divided into three categories: informed traders, uninformed technical traders, and uninformed noise traders. Likewise, the investors who trade in the futures market can also be classified based on this concept. However, for investors in the futures market, apart from the three categories above, we also have one special category, namely, arbitragers. The arbitragers are the investors who trade in both the stock market and the stock index futures market, making profits from the price fluctuation between these two markets. Specifically speaking, the arbitragers would open short positions in the index futures market and buy the spot stock index simultaneously when they notice that the futures price is higher than the upper limit of the nonarbitrage price. Moreover, the arbitragers would calculate their profits every single day. Both the stock and futures position will be offset; that is, if expected return is achieved, they will sell the stock index and buy the futures contract or they will not offset the position and wait until the futures contract expires. In our model, in order to execute market order promptly, the arbitragers will allocate their money properly between the stock market and futures market according to their wealth (total asset), making risk-free profits. The trading behavior and strategy for all the investors can be referred from Zhang et al. (2011) and Chiarella et al. (2009) [22].

4.2. Model Parameters Setting. There are 60522 subperiods in every experiment period, which represent 21 days. Each day has 2882 subperiods, and one subperiod stands for 5 seconds in the real world. The risk-free interest rate is $4.26 \%$, the same number as the interbank collateral repo rate. The positions for the stock and futures market should be closed out at the end of trading day. The minimum trade requirement for the stock market is one lot, namely, 100 shares, and short selling in the stock market is prohibited. The tick size (minimum price fluctuation) is 1 cent and 20 cents for the stock market and futures market, respectively. Daily price fluctuation limit for both markets is set up as $10 \%$. The commission fee for the stock market and futures market is $0.3 \%$ and $0.005 \%$, respectively. The impact cost during the arbitrage is supposed to be $0.21 \%$ and $0.015 \%$ for the stock market and futures market, respectively. The maximum allowed position for the stock index futures market is 100 lots, and the margin ratio could be as low as $12 \%$. The multiplier for the stock index futures is 300 .

\subsection{Simulation Experiment Results}

4.3.1. Probability of Informed Trading and Market Absolute Yield. Existing empirical studies show that, in the same market investor's structural framework, with VPIN gradually increasing, the share of its subsequent market's low absolute yields reduces gradually, while the proportion of high absolute yields increases. Method of agent-based computational finance makes it possible to clarify the relationships between VPIN and market absolute yields under different proportion of informed traders. And the structure of investors in financial markets can be characterized by the proportion of various investment strategies. Proportions of informed investors in this study are designed as follows: $1 / 6,1 / 3,1 / 2,2 / 3$, and 5/6. In order to be consistent with the reality, experiments do not consider two extreme conditions; that is, there are no informed traders existing in the market and the proportion of informed traders reaches $100 \%$.

Analysis of data statistics can be divided into twenty groups; each group contains 5\% observations. Take the first column; for example, this row is sorted in ascending order according to the informed trading probability. The first line stands for the absolute yield, and then we divide data into eight groups according to the absolute yields from the lowest to the highest. Due to space constraints, we can not list all the statistics. Therefore, we, respectively, select the information investors' proportion between $1 / 6$ and 5/6 as representative sample. Tables 1 and 2 show the results.

According to above-mentioned analytical results, for the same investor structure, with VPIN which is gradually increasing, the share of its subsequent market's low absolute yields gradually decreases, while the proportion of high absolute yields increases. This is consistent with empirical research findings based on the real market. Thus, for different investor structure, with the increase of informed traders in the market, the market absolute yields corresponding to larger VPIN value show a tendency of increasing. This suggests that when the market traders are usually informed traders, risk events will impact the market to a greater extent, because liquidity traders face increasing adverse selection cost when dealing with informed traders.

4.3.2. Proportion of Informed Traders and Market Quality. This section mainly studies the impacts from the proportion of informed traders on market information dissemination efficiency and market liquidity, and we choose market information dissemination efficiency from Gil-Bazo et al. (2007) [23] and Zhang et al. (2011) as the indicators. Market liquidity is represented by the turnover rate of market limit orders (a limit pay can be a market order when its price is higher than the best selling price, and a limit sell order can be a market order when its price is lower than optimal bid price. Statistical results exclude those limit orders used as market orders); the formula is as follows:

$$
\operatorname{MAE}=\frac{1}{T} \sum_{t=1}^{T}\left|p_{t}-v_{t}\right|
$$

As can be seen from Table 3, when the proportion of informed traders is between $1 / 3$ and $1 / 2$, market information dissemination efficiency becomes better and the turnover rate of limit orders also rises, while in many other cases, market information dissemination efficiency and the turnover rate of limit orders are showing a deteriorating trend. This indicates that, when the proportion of informed traders is between $1 / 3$ and $1 / 2$, market transparency and market liquidity are better. 
TABLE 1: Absolute yields under VPIN conditions when the proportion of informed investors is 1/6.

\begin{tabular}{|c|c|c|c|c|c|c|c|c|}
\hline & 0.0015 & 0.003 & 0.0045 & 0.006 & 0.0075 & 0.009 & 0.0105 & $>0.0105$ \\
\hline 0.00011 & $68.00 \%$ & $24.00 \%$ & $6.00 \%$ & $0.00 \%$ & $2.00 \%$ & $0.00 \%$ & $0.00 \%$ & $0.00 \%$ \\
\hline 0.00488 & $40.00 \%$ & $30.00 \%$ & $18.00 \%$ & $8.00 \%$ & $4.00 \%$ & $0.00 \%$ & $0.00 \%$ & $0.00 \%$ \\
\hline 0.10538 & $50.00 \%$ & $28.00 \%$ & $12.00 \%$ & $4.00 \%$ & $4.00 \%$ & $2.00 \%$ & $0.00 \%$ & $0.00 \%$ \\
\hline 0.17095 & $46.00 \%$ & $34.00 \%$ & $10.00 \%$ & $2.00 \%$ & $8.00 \%$ & $0.00 \%$ & $0.00 \%$ & $0.00 \%$ \\
\hline 0.29997 & $50.00 \%$ & $24.00 \%$ & $12.00 \%$ & $2.00 \%$ & $4.00 \%$ & $2.00 \%$ & $0.00 \%$ & $6.00 \%$ \\
\hline 0.43789 & $50.00 \%$ & $26.00 \%$ & $4.00 \%$ & $4.00 \%$ & $10.00 \%$ & $2.00 \%$ & $0.00 \%$ & $4.00 \%$ \\
\hline 0.5009 & $48.00 \%$ & $16.00 \%$ & $14.00 \%$ & $6.00 \%$ & $6.00 \%$ & $0.00 \%$ & $0.00 \%$ & $10.00 \%$ \\
\hline 0.55039 & $42.00 \%$ & $30.00 \%$ & $12.00 \%$ & $4.00 \%$ & $4.00 \%$ & $2.00 \%$ & $0.00 \%$ & $6.00 \%$ \\
\hline 0.58429 & $55.50 \%$ & $20.67 \%$ & $9.83 \%$ & $5.33 \%$ & $2.67 \%$ & $1.17 \%$ & $1.33 \%$ & $3.50 \%$ \\
\hline 0.61272 & $55.82 \%$ & $20.73 \%$ & $9.64 \%$ & $5.45 \%$ & $2.55 \%$ & $1.27 \%$ & $1.27 \%$ & $3.27 \%$ \\
\hline 0.64318 & $55.40 \%$ & $20.80 \%$ & $9.60 \%$ & $5.20 \%$ & $2.60 \%$ & $1.40 \%$ & $1.40 \%$ & $3.60 \%$ \\
\hline 0.67021 & $56.67 \%$ & $19.33 \%$ & $9.78 \%$ & $5.11 \%$ & $2.89 \%$ & $1.33 \%$ & $1.33 \%$ & $3.56 \%$ \\
\hline 0.69265 & $57.25 \%$ & $19.25 \%$ & $10.00 \%$ & $5.00 \%$ & $2.75 \%$ & $1.00 \%$ & $1.25 \%$ & $3.50 \%$ \\
\hline 0.71589 & $56.57 \%$ & $18.86 \%$ & $11.14 \%$ & $5.71 \%$ & $2.29 \%$ & $0.86 \%$ & $1.43 \%$ & $3.14 \%$ \\
\hline 0.73141 & $55.67 \%$ & $19.33 \%$ & $11.67 \%$ & $5.67 \%$ & $2.33 \%$ & $0.67 \%$ & $1.33 \%$ & $3.33 \%$ \\
\hline 0.74439 & $54.80 \%$ & $19.60 \%$ & $11.20 \%$ & $5.60 \%$ & $2.40 \%$ & $0.80 \%$ & $1.60 \%$ & $4.00 \%$ \\
\hline 0.75569 & $54.50 \%$ & $19.00 \%$ & $11.50 \%$ & $6.50 \%$ & $2.00 \%$ & $1.00 \%$ & $1.00 \%$ & $4.50 \%$ \\
\hline 0.76385 & $51.33 \%$ & $20.67 \%$ & $11.33 \%$ & $6.67 \%$ & $2.67 \%$ & $0.67 \%$ & $0.67 \%$ & $6.00 \%$ \\
\hline 0.77579 & $53.00 \%$ & $24.00 \%$ & $8.00 \%$ & $8.00 \%$ & $1.00 \%$ & $1.00 \%$ & $0.00 \%$ & $5.00 \%$ \\
\hline 0.79111 & $48.00 \%$ & $28.00 \%$ & $10.00 \%$ & $8.00 \%$ & $0.00 \%$ & $2.00 \%$ & $0.00 \%$ & $4.00 \%$ \\
\hline
\end{tabular}

TABLE 2: Absolute yields under VPIN conditions when the proportion of informed investors is 5/6.

\begin{tabular}{lcccccccc}
\hline & 0.0015 & 0.003 & 0.0045 & 0.006 & 0.0075 & 0.009 & 0.0105 & $>0.0105$ \\
\hline 0.0053 & $74.00 \%$ & $18.00 \%$ & $8.00 \%$ & $0.00 \%$ & $0.00 \%$ & $0.00 \%$ & $0.00 \%$ & $0.00 \%$ \\
0.029766 & $74.00 \%$ & $20.00 \%$ & $6.00 \%$ & $0.00 \%$ & $0.00 \%$ & $0.00 \%$ & $0.00 \%$ & $0.00 \%$ \\
0.049642 & $56.00 \%$ & $28.00 \%$ & $10.00 \%$ & $4.00 \%$ & $2.00 \%$ & $0.00 \%$ & $0.00 \%$ & $0.00 \%$ \\
0.085005 & $64.00 \%$ & $32.00 \%$ & $2.00 \%$ & $0.00 \%$ & $2.00 \%$ & $0.00 \%$ & $0.00 \%$ & $0.00 \%$ \\
0.142565 & $58.00 \%$ & $12.00 \%$ & $14.00 \%$ & $10.00 \%$ & $6.00 \%$ & $0.00 \%$ & $0.00 \%$ & $0.00 \%$ \\
0.242377 & $44.00 \%$ & $22.00 \%$ & $16.00 \%$ & $6.00 \%$ & $8.00 \%$ & $4.00 \%$ & $0.00 \%$ & $0.00 \%$ \\
0.304469 & $52.00 \%$ & $24.00 \%$ & $8.00 \%$ & $10.00 \%$ & $0.00 \%$ & $2.00 \%$ & $0.00 \%$ \\
0.38123 & $40.00 \%$ & $26.00 \%$ & $12.00 \%$ & $8.00 \%$ & $4.00 \%$ & $0.00 \%$ & $2.00 \%$ \\
0.516074 & $32.00 \%$ & $22.33 \%$ & $14.67 \%$ & $11.67 \%$ & $4.83 \%$ & $4.83 \%$ & $3.17 \%$ & $8.00 \%$ \\
0.61289 & $30.55 \%$ & $21.82 \%$ & $15.45 \%$ & $11.82 \%$ & $5.09 \%$ & $5.09 \%$ & $3.09 \%$ & $6.50 \%$ \\
0.645069 & $30.80 \%$ & $21.60 \%$ & $14.20 \%$ & $12.40 \%$ & $5.40 \%$ & $5.40 \%$ & $3.00 \%$ & $7.09 \%$ \\
0.686656 & $30.67 \%$ & $22.00 \%$ & $14.67 \%$ & $12.22 \%$ & $5.33 \%$ & $5.56 \%$ & $3.33 \%$ \\
0.703128 & $30.50 \%$ & $21.50 \%$ & $15.00 \%$ & $12.25 \%$ & $5.75 \%$ & $5.75 \%$ & $3.00 \%$ \\
0.726787 & $30.57 \%$ & $22.00 \%$ & $15.43 \%$ & $12.29 \%$ & $4.86 \%$ & $5.43 \%$ & $3.14 \%$ & $6.22 \%$ \\
0.751038 & $31.67 \%$ & $20.00 \%$ & $14.67 \%$ & $12.33 \%$ & $4.67 \%$ & $6.33 \%$ & $3.33 \%$ \\
0.793769 & $30.80 \%$ & $20.40 \%$ & $15.20 \%$ & $12.80 \%$ & $4.80 \%$ & $7.20 \%$ & $2.40 \%$ & $7.00 \%$ \\
0.819723 & $29.50 \%$ & $21.00 \%$ & $16.50 \%$ & $13.50 \%$ & $5.50 \%$ & $6.00 \%$ & $3.00 \%$ & $6.40 \%$ \\
0.84226 & $30.00 \%$ & $18.67 \%$ & $17.33 \%$ & $14.67 \%$ & $5.33 \%$ & $6.00 \%$ & $3.33 \%$ & $5.00 \%$ \\
0.854557 & $29.00 \%$ & $16.00 \%$ & $22.00 \%$ & $14.00 \%$ & $4.00 \%$ & $7.00 \%$ & $4.00 \%$ & $4.67 \%$ \\
0.878799 & $24.00 \%$ & $18.00 \%$ & $30.00 \%$ & $10.00 \%$ & $6.00 \%$ & $8.00 \%$ & $2.00 \%$ & $2.00 \%$ \\
\hline
\end{tabular}

\section{Conclusion}

In this paper, we adopt the TBS-ASIFM model established by Zhang et al. (2011) to study probability of informed trading of stock index futures market and its effect on subsequent market absolute yields, respectively, and also give a detailed description of the market information dissemination efficiency and dynamic characteristics of liquidity under different traders structure. We find that, on one hand, as for the same traders' structure, with the probability of informed trading increasing gradually, the share of the low absolute yields in subsequent market gradually decreases, while the 
TABLE 3: Statistical results in each experimental group.

\begin{tabular}{lccc}
\hline Experimental group & Proportion of informed traders & MAE & Turnover rate of limit order \\
\hline 1 & $1 / 6$ & 8.64 & $30.67 \%$ \\
2 & $1 / 3$ & 6.06 & $20.45 \%$ \\
3 & $1 / 2$ & 2.85 & $32.06 \%$ \\
4 & $2 / 3$ & 12.95 & $12.94 \%$ \\
5 & $5 / 6$ & 16.43 & $12.40 \%$ \\
\hline
\end{tabular}

proportion of high absolute yields gradually increases. As for different traders' structures, increase in informed traders on the market facilitates the increasing tendency of the market absolute yields. On the other hand, we also find that there will be better transparency and liquidity of the market when the proportion of informed traders accounts for between $1 / 3$ and $1 / 2$ by focusing on market information dissemination efficiency and liquidity under different trader's structures.

\section{Research Prospects}

In this paper, we apply VPIN model and agent-based computational finance to analyze information transactions, but there are still some issues to be further studied.

Firstly, VPIN model used in this paper is based on the market-maker market; although this model is of universal applicability and transplantability, new methods based on continuous auction market to estimate probability of informed trading are still to be drilled down into.

Secondly, VPIN model can be a warning of market liquidity risk; this paper only gives our own explanations on the most superficial level and does not explore the concrete impact mechanism.

Thirdly, we can further expand TBS-ASIFM model, invert the "flash crash" event, and study the effectiveness of market regulatory measures (e.g., transaction contracts of VPIN).

\section{Conflict of Interests}

The authors declare that there is no conflict of interests regarding the publication of this paper.

\section{Acknowledgments}

This paper was supported by NSFC (nos. 71131007 and 71271145), Program for Changjiang Scholars and Innovative Research Team in University (no. IRT1028), and Specialized Research Fund for the Doctoral Program of Higher Education (no. 20110032110031).

\section{References}

[1] D. Easley, M. M. L. de Prado, and M. O’Hara, "Flow toxicity and volatility in a high frequency world," Review of Financial Studies, vol. 25, no. 5, pp. 1457-1493, 2011.

[2] J. L. Holland, Making Vocational Choices: A Theory of Vocational Personalities and Work Environments, Psychological Assessment Resources, Odessa, Fla, USA, 1997.
[3] D. Easley, N. M. Kiefer, M. O'Hara, and J. B. Paperman, "Liquidity, information, and infrequently traded stocks," Journal of Financeno, vol. 51, no. 4, pp. 1405-1436, 1996.

[4] D. Easley, N. M. Kiefer, and M. O'Hara, “The information content of the trading process," Journal of Empirical Finance, vol. 4, no. 2-3, pp. 159-186, 1997.

[5] J. H. Venter and D. de Jongh, "Extending the EKOP model to estimate the probability of informed trading," Studies in Economics and Econometrics, vol. 30, no. 2, pp. 25-39, 2006.

[6] Q. Lei and G. Wu, "Time-varying informed and uninformed trading activities," Journal of Financial Markets, vol. 8, no. 2, pp. 153-181, 2005.

[7] D. Easley, M. M. L. de Prado, and M. O’Hara, “The volume clock: insights into the high frequency paradigm," The Journal of Portfolio Management, vol. 39, no. 1, pp. 19-29, 2012.

[8] K. Nyholm, "Estimating the probability of informed trading," Journal of Financial Research, vol. 25, no. 4, pp. 485-505, 2002.

[9] K. Nyholm, "Inferring the private information content of trades: a regime-switching approach," Journal of Applied Econometrics, vol. 18, no. 4, pp. 457-470, 2003.

[10] D. Easley, M. M. L. de Prado, and M. O’Hara, “The microstructure of the flash crash: flow toxicity, liquidity crashes and the probability of informed trading," The Journal of Portfolio Management, vol. 37, no. 2, pp. 118-128, 2011.

[11] C. Huang, X. Gong, X. Chen, and F. Wen, "Measuring and forecasting volatility in Chinese stock market using HAR-CJ-M model," Abstract and Applied Analysis, vol. 2013, Article ID 143194, 13 pages, 2013.

[12] H. Levy, M. Levy, and S. Solomon, Microscopic Simulation of Financial Markets: From Investor Behavior to Market Phenomena, Academic Press, San Diego, Calif, USA, 2000.

[13] B. LeBaron, "Agent-based financial markets: matching stylized facts with style," in Post Walrasian Macroeconomics: Beyond the DSGE Model, D. Colander, Ed., pp. 221-235, Cambridge University Press, 2006.

[14] L. Tesfatsion and K. L. Judd, "Agent-based computational finance," in Handbook of Computational Economics, vol. 2, chapter 16, pp. 831-880, North-Holland, Amsterdam, The Netherlands, 2006.

[15] T. Lux and M. Marchesi, "Scaling and criticality in a stochastic multi-agent model of a financial market," Nature, vol. 397, no. 6719, pp. 498-500, 1999.

[16] S. Mike and J. D. Farmar, "An empirical behavioral model of liquidity and volatility," Journal of Economic Dynamics and Control, vol. 32, no. 1, pp. 200-234, 2008.

[17] G. F. Gu and W. X. Zhou, "Emergence of long memory in stock volatility from a modified Mike-Farmer model," Europhysics Letters, vol. 86, no. 4, article 48002, 6 pages, 2009. 
[18] Y. J. Zhang, W. Zhang, and X. Xiong, "Investment strategies and yield: based on the calculation of financial research experiments," Journal of Management Sciences in China, vol. 13, no. 009, pp. 107-118, 2010.

[19] X. Xiong, M. Wen, W. Zhang, and Y. J. Zhang, "Cross-market financial risk analysis: an agent-based computational finance," International Journal of Information Technology and Decision Making, vol. 10, no. 3, pp. 563-584, 2011.

[20] W. Zhang, X. Xiong, and L. J. Wei, "Analysis of market-based trading mechanisms computational experiment finance stock index futures," China Financial Futures Exchange Research Report, 2011.

[21] D. Easley, R. F. Engle, and M. O’Hara, “Time-varying arrival rates of informed and uninformed traders," Journal of Financial Econometrics, vol. 6, no. 2, pp. 171-207, 2008.

[22] C. Chiarella, G. Iori, and J. Perelló, "The impact of heterogeneous trading rules on the limit order book and order flows," Journal of Economic Dynamics and Control, vol. 33, no. 3, pp. 525-537, 2009.

[23] J. Gil-Bazo, D. Moreno, and M. Tapia, "Price dynamics, informational efficiency, and wealth distribution in continuous double-auction markets," Computational Intelligence, vol. 23, no. 2, pp. 176-196, 2007. 


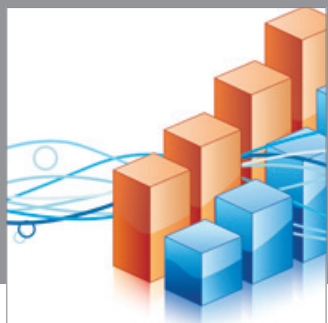

Advances in

Operations Research

mansans

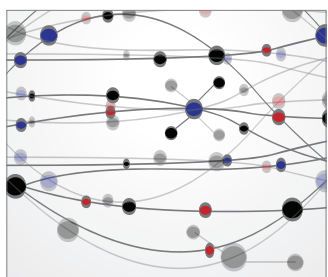

The Scientific World Journal
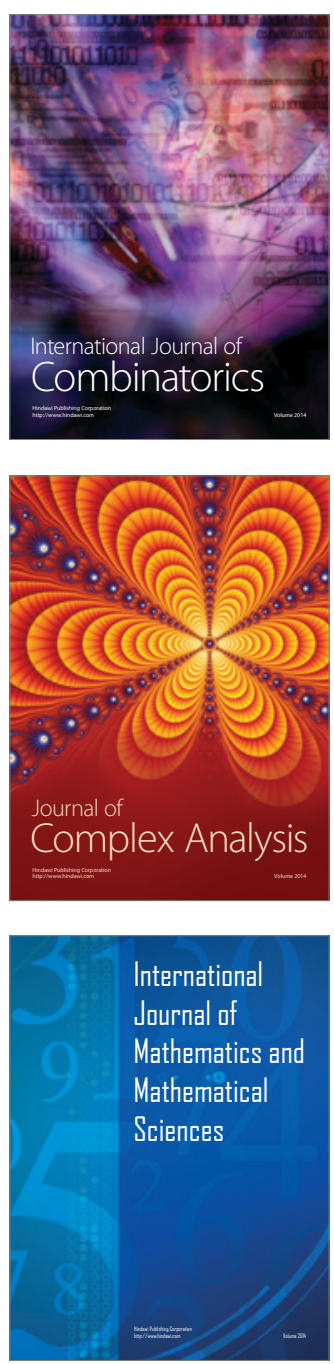
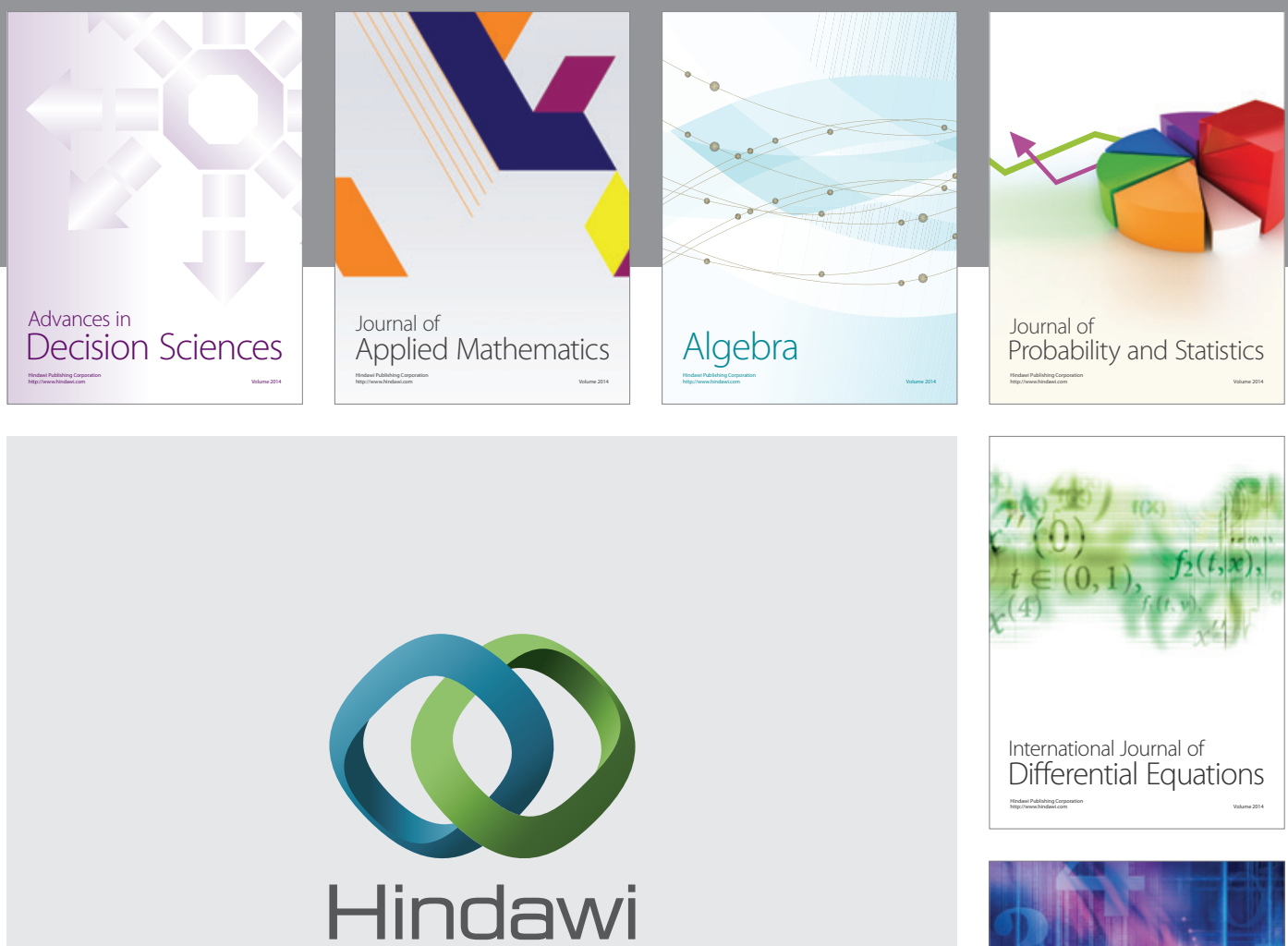

Submit your manuscripts at http://www.hindawi.com
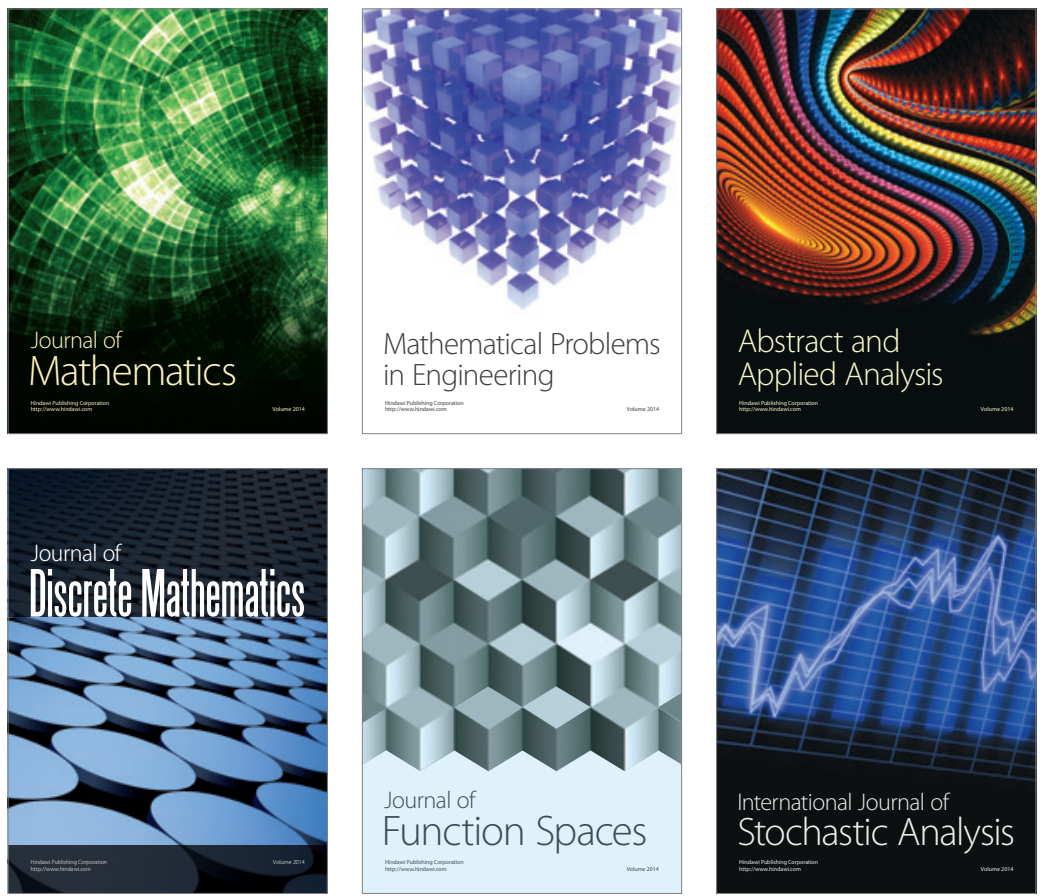

Journal of

Function Spaces

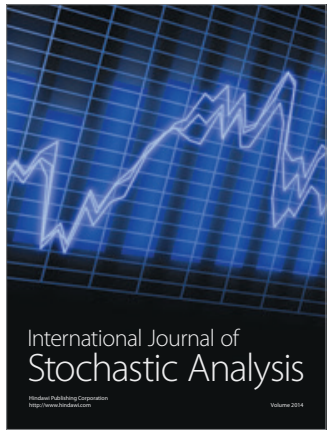

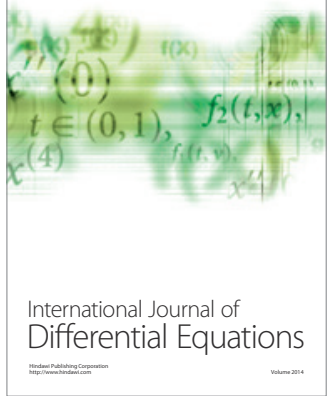
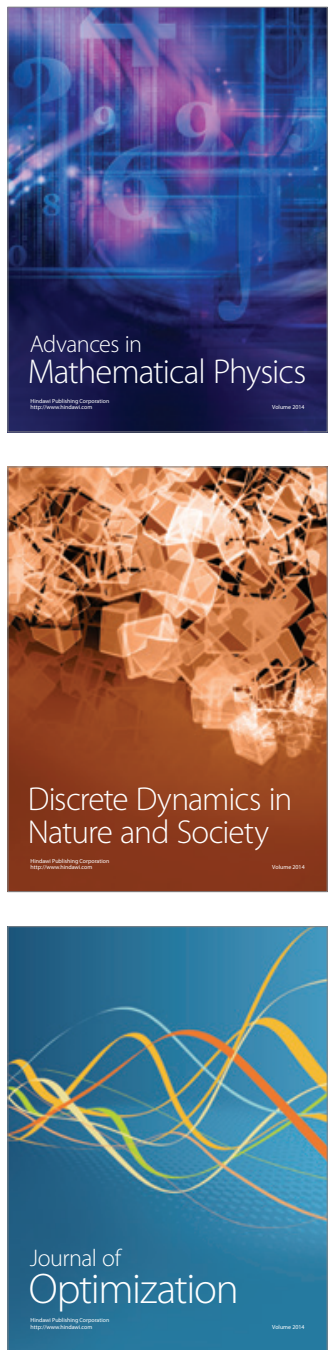